\title{
Connecting opinion, belief and value: semantic network analysis of a UK public survey on embryonic stem cell research
}

\section{Leo Kim and Namhyeok Kim}

\begin{abstract}
This study re-examines the survey responses of embryonic stem cell research prepared for UK Department of Health (DH) in 2006. Aided by the novel method of semantic network analysis, the main purpose of the reanalysis is to "re-present" the overlooked layer of public opinion with respect to embryonic stem cell research, and to reflect on the under-represented public opinion. This critical review attempts to shed light on potential concerns of the UK public in the face of emerging life science policy. The article argues that a new way to encourage people's articulation and engagement in science policy should be discussed. This means more active incorporation of concepts that represent people's opinion, belief and value in research. By applying semantic network analysis, we introduce an effective way to visualize and evaluate people's core frame of embryonic stem cell research.
\end{abstract}

\section{Keywords}

Public participation, Stem cell resesarch, Survey, Semantic network analysis

On 16 August 2005, the UK Department of Health (DH) launched a public consultation as part of its review of the Human Fertilisation and Embryology Act 1990. The Human Fertilisation and Embryology Act (hereafter HFEA) permits research on early embryos, but only when the study is strictly dedicated to improving human reproduction or fertility. The act was part of a debate ongoing in the UK since the creation of Dolly in 1997 [Durant, Bauer and Gaskell, 1998].

After an earlier public consultation on the ethical aspect of animal cloning was set up jointly by the HFEA and the Human Genetics Advisory Commission, the ensuing report [Human Genetics Advisory Commission, 1998] concluded that the Human Fertilisation and Embryology Act had proved effective in dealing with new developments relating to human cloning. The legislative installment, however, seemed less convincing to those who saw how quickly the field was advancing. In April 2002, the House of Commons Science and Technology Committee concluded that it was necessary to "reconnect the Act with modern science" [House of Commons, 2002, p. 13]. The UK Department of Health ultimately agreed, announcing on 21 January 2004 a review of the Human Fertilisation and 
Embryology Act. The eventual report, "Human Reproductive Technologies and the Law," issued on March 2005, laid out the government policy regarding the controversial areas of embryo research, including interspecies transplantation [UK Department of Health, 2005; Kim, 2012].

The issues covered in the $\mathrm{DH}$ review had been much rehearsed over the years; the consultation was regarded as part of a larger exercise that explored societal views and stimulated debate about ideas such as: the model and scope of regulation; child welfare; the use and storage of gametes and embryos; reproductive choices of screening and selection; information and the HFEA register; surrogacy; legal status of parenthood; regulatory authority for tissues and embryos; and human embryonic stem cell research [PSP, March 2006]. In retrospect, the consultation and the summary of people's opinions, with a few other contemporary surveys, ${ }^{1}$ placed a significant milestone: they entrenched the Science and Technology Committee's view supporting the Warnock Commission's approach to the status of the embryo [UK Department of Health and Social Security, 1984]. This provided the government grounds for not revisiting fundamental aspects of the existing law [UK Department of Health, 2005, p. 5-8], by stating:

\begin{abstract}
"Human Reproductive Technologies and the Law" provided a prohibition of any form of reproductive cloning, it is important that it is supported by principled arguments why such a technique should be banned even if it were shown to be safe, effective and reliable. Without such arguments, an indefinite absolute ban could not be considered rational".
\end{abstract}

In other words, mere popular concern is not sufficient reason to rule out an area of research, and "alleged harms to society or to patients need to be demonstrated before forward progress is unduly impeded" [Kim, 2012]. As to the emerging issue of chimeras and hybrids, the committee adopted the same line of argument, saying:

\begin{abstract}
"The ethical status of hybrids and chimeras is complex. While there is revulsion in some quarters that such creations appear to blur the distinction between animals and humans, it could be argued that they are less human than, and therefore pose fewer ethical problems for research than fully human embryos. We recognise concerns that hybrids and chimeras could be used for reproductive purposes and recommend that new legislation a) defines the nature of these creations, b) makes their creation legal for research purposes if they are destroyed in line with the current 14-day rule for human embryo cultures, and c) prohibits their implantation in a woman". [UK Department of Health, 2005, p. 10]
\end{abstract}

The government consultation and ensuing report commissioned to People Science \& Policy Ltd (PSP) collected 535 responses in total, ${ }^{2}$ and qualitatively analyzed the

\footnotetext{
${ }^{1}$ In 2004 the Human Genetics Commission (HGC) launched a public consultation on "Choosing the Future: genetics and reproductive decision-making" which received 196 responses. In August 2005 the Daily Telegraph reported the results of a YouGov Survey covering similar questions (29 August 2005). The Market and Opinion Resesarch International (MORI) survey of 1840 adults was conducted in March 2005 for the HFEA to touch on similar areas of reproductive technology.

${ }^{2}$ They are stored as PDF format and publically accessible in the UK government archive. Link: http:/ / collections.europarchive.org/tna/20100509080731/http:/ /dh.gov.uk/en/Consultations / Responsestoconsultations/DH_4132358.
} 
408 electronically received consultation responses based on the "Grounded Theory" technique [Strauss and Corbin, 1990]. According to the report, the purpose was:

\begin{abstract}
"to attempt to crystallize the key streams of argument around a particular subject and to characterize those arguments into these which then form an overall landscape of the debate around a subject", while not intending "to quantify frequencies of argument or to generalize about particular actor groups" [PSP, March 2006, p. 1].
\end{abstract}

The summary gave an overview of the issues that each topic raised mainly by selectively citing responses, but "no conclusions [were] reached as it was believed more appropriate to give an overview of the landscape of arguments rather than attempt to draw conclusions from such disparate responses" [PSP, March 2006, p. 2]. A year later, the consultation was criticized by the OPM in a report titled "Stem Cell Public Dialogue", commissioned by Biotechnology and Biological Sciences Research Council (BBSRC) and the Medical Research Council (MRC). The OPM report argued that the consultation "often conflated opinions regarding embryos for treatment and embryos for research". The report also noted:

\begin{abstract}
"the consultation gives no indication of the numbers of responses on either side of any debate, as the consultation was not seen to be representative. As such, no overall view can be gained of people's attitudes [OPM, 2007, p. 12, emphasis by the original documen]".
\end{abstract}

The somewhat predictable criticism expressed by the OPM report, calls for a methodological alternative to revisit the existing data, while not ruling out the traditional qualitative method. In this article, we aim to present a way to combine automated analysis of textual data and qualitative analysis to deliver the overall landscape of public opinion in a more structured way. By examining both the survey responses and the summary of the PSP report prepared for Department of Health, while focusing on the topic of embryonic stem cell research, we attempt to a) "re-present" the overlooked layer of public opinion with respect to embryonic stem cell research, b) reflect on the characteristics of under-represented public opinion, and to c) shed light on potential concerns of the UK public faced with emerging life science policy. From a methodological persepctive, we argue that effective use of semantic network analysis could lead to discovery of both general and particular aspects of public opinion, derived from open-questionnaire survey data, that might be difficult to capture with more traditional research methods.

Reviewing research on the public's participation in stem cell policy in the UK, we want to ask: "How much has the public been empowered to articulate their opinions, regardless of the formal institution for public participation in science policy?". Especially considering Bourdieu [1991]'s discussion of symbolic power or Foucault's Foucault [2002] discussion of power in discourse, we believe that this question can highlight not only the formal power structure in a society, but the way certain concepts gain weight over others and exercise socio-political power. As will be explained in the Methodology section, the applied semantic network analysis may visualize the assemblage of concepts in a discourse, measuring their relative weights and evaluating their connections. 
Review of previous analysis
In the UK government survey, responses to the consultation were many and varied: in total there were 535 responses, including some from organizations/groups and individual professionals involved in medical or legal practice in the relevant area and others from individual members of the public [PSP, March 2006, p. 1]. The consultation document covered a wide range of issues and asked 74 specific questions. Among the total of 74 questionnaires of the $\mathrm{DH}^{\prime}$ 's public consultation covering various topics of life science, 9 questions below are directly related to the issue of endorsing embryo and stem cell research that are subject to our review. During the survey, the respondents, both interested individuals and organizations, were required to respond to the government's current position expressed as statements:

57. In common with the Science and Technology Committee, the Government believes that there is no case at present for either an extension or a reduction to the 14 day time limit for keeping an embryo. Any change would remain a matter for Parliament.

58. The Government believes that research undertaken on embryos using the cell nuclear replacement technique for the purpose of studying mitochondrial diseases should be permissible in law, subject to licensing.

59. Further, the Government invites views on removing the current prohibition on "replacing a nucleus of a cell of an embryo with a nucleus taken from the cell of any person, another embryo or a subsequent development of an embryo" for research purposes, subject to licensing.

60. The Government invites views on whether the law should permit altering the genetic structure of an embryo for research purposes, subject to licensing.

61. The Government invites views on whether the law should permit the creation of human-animal hybrid or chimera embryos for research purposes only (subject to the limit of 14 days culture in vitro, after which the embryos would have to be destroyed).

62. The Government invites views on whether the current list of legitimate purposes for licensed research involving embryos remains appropriate.

63. The Government believes that the purposes for which research using embryos may legitimately be undertaken should, as now, be defined in law and research projects should continue to be approved by a national body in order to ensure compliance with the law, national consistency and appropriate ethical oversight.

64. The Government invites views on what, if any, additional regulatory requirements should apply to the procurement and use of gametes for purposes of research.

65. The Government invites comments on the desirability of allowing the creation of embryos for the treatment of serious diseases (as distinct from research into developing treatments for serious diseases which is already allowed).

After data analysis of the 408 electronically received responses, the PSP report summarized that some responses disagreed with the Government position favoring a 14-day limit for keeping an embryo (Q. 25, p. 66). With respect to the usage of cell 
nuclear replacement $(\mathrm{CNR})$ technique $(\mathrm{Q} .58 ; 59)$, the report notes that there were mixed views and some feared that this could lead to human cloning (p. 68). On altering the genetic structure of an embryo (Q. 60), the PSP reported opposing voices: the School of Theology, Philosophy and History and Minister of Religion, (p. 68) believing it would result in germ-line alterations and possibly lead to eugenics, constrasted with the Medical Research Council and The Academy of Medical Sciences, (p. 69) believing that advances through such research could be beneficial.

As to the matter of the controversial human-animal hybrid and chimera embryos (Q. 61), the summary describes a number of responses which urged that the law should prevent the creation of human-animal hybrid or chimera embryos for research purposes. The notion of the "special status" of human life as a reason for the prohibition of this research was introduced, as well as fears that a new species would be created; wider social and ethical issues were also discussed (citations from an individual contributor and the Church of Scotland, p. 69). To balance, it notes that those who supported the creation of human-animal hybrid and chimera embryos thought there was potential for developments in research (citations from the Academy of Medical Sciences and another individual respondent, p. 69). For the purposes for which research may be permitted (Q. 62), it concludes that a number of respondents thought that the current list was appropriate; however, many considered the list to be too restrictive, lacking flexibility in a fast moving area of research (p. 70). Finally, as to the essential question of creating embryos for therapeutic purposes (Q. 65), the section closes with comments on the wide ranging responses about the desirability of allowing the creation of embryos for treatment of serious diseases; many who disagreed with the creation of embryos for treatment disagreed in principle with creation of embryos for research purposes (pp. 72-73). The PSP report did not quantify the responses but merely used terms such as "many people" or "some respondents".

In order to trace implications from the 408 electronic responses, after preliminary reading of the texts, the two authors categorized the opinions into five characteristic parts (a. entirely agree; b. agree with reservation; c. generally disagree; $d$. entirely disagree; and e. others) and quantified their proportions. When there was a difference of opinion that seldom occurred (twice), we put them in the category of Others. In general, people's attitude reviewed in this way turned out to have clear boundaries of opinions. With very few exceptions, it transpired that those who "agree with reservation" do so except for "the creation of human-animal hybrid or chimera embryos for research purposes only" (Q. 61). On the other hand, people who "disagree with stem cell research" disagree with stem cell research but do not explicitly raise dissent or doubt against the 14-day time limit for keeping an embryo and licensing regime for embryo research, whilst those who "entirely disagree" assert that both the 14-day time limit rule (Q. 57) and the government licensing system of the research (Q. 62; 63; 64) are arbitrary, unscientific and problematic. The others are those who refused to answer or did not answer for another unknown reason.

Figure 1 shows that only 44 people (11\%) entirely agree with the research, 40 people $(10 \%)$ agree with overall research but disagree with the creation of human-animal hybrid or chimera embryos, 74 people $(18 \%)$ generally disagree with all the relevant research save the already established licensing regime for the embryo 
research, and 67 people (16\%) disagreed in principle with not only the creation of embryos for research purposes but also related governing mechanism and institutions in the UK. Among those who responded to the statement no. 61 asking "whether the law should permit the creation of human-animal hybrid or chimera embryos for research purposes only", most (181) said "no".

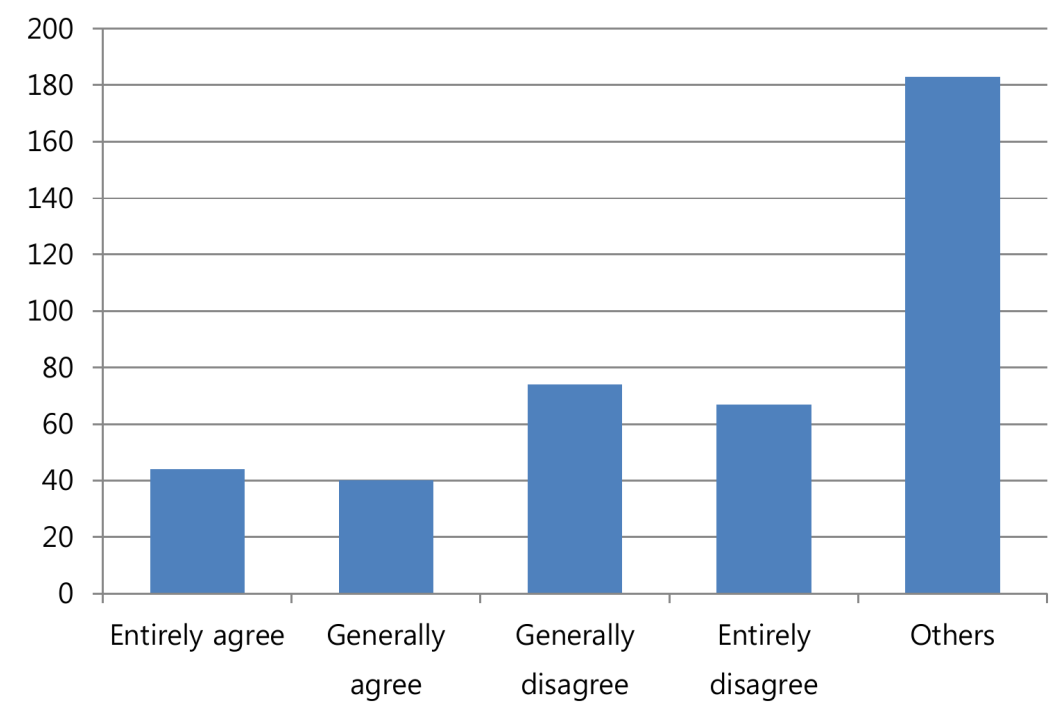

(a) Opinion on embryo \& stem cell research

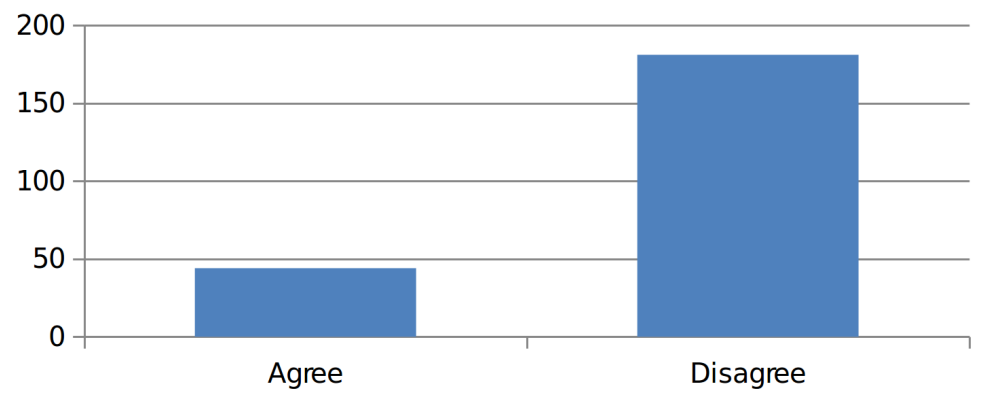

(b) Opinion of hybrid \& chimera embryo

Figure 1. Quantified opinion regarding embryo \& stem cell research.

There is good reason for the OPM to accuse the authors of the PSP report "conflation" [OPM, 2007, p. 13] regarding embryos for treatment and research, especially when considering the overwhelming disagreement against the hybrid \& chimera embryo. The gap between summary and numbers hints at the possibility that the data could yield more, especially regarding people's understanding and feelings about the emerging life science and their underlying values. What should be investigated further, supported by alternative methodologies, is the overall description of respondents' core concepts, and the way they frame stem cell research.

An interesting point we can observe from the quantified result is that there certainly is a salience of opinion among the respondents, in contrast to the neutralizing conclusion of the PSP report, in regard to some specific issues. In particular, the dominant majority disagreed with hybrid and chimera embryo research, but this important aspect was negelected in the previous research. This fact leads us to more serious questioning: "Was the previous qualitative research sufficient to represent the structured opinion patterns?" The authors believed that 
more intuitive characteristics could be discovered from the existing data, and propose an alternative methodology to derive the pattern.

As Sheila Jasanoff Jasanoff [2005, pp. 250-256] points out, when discussing the importance of civic epistemology in scientific governance, "surveys do not just test respondents' understanding of science: they simultaneously construct the respondent as a particular kind of knower, or in this case a nonknower". Some survey methods can be utilized as a device to legitimize assumptions of state elites, whereas some qualitative analysis might reveal relations hidden beneath the spurious categorical relationships. The questionnaires designed by the $\mathrm{DH}$, as we have seen, are restrictive in that they represent the established government schemes that require some significant level of legal and scientific knowledge to understand. Therefore, responses are invariably framed within this construction. Still, a certain degree of freedom, despite the constrictions of the survey, may be observed in people's expressions. We argue that an alternative research perspective could reveal hidden structures, adequately aligning qualitative and quantitative methods.

Merging the focus on textual information of the psychological tradition and the sociological concern with the construction of meaning, most contemporary views of framing focus on variations in the semantic context of information [Tewksbury and Scheufele, 2009]. The main characteristics of the frame can be summarized in three ways: first, frames involve selectivity, rendering some aspects of an issue salient. Second, frames give meaning by following some central organizing idea. Third, frames perform argumentative functions: they define situations, establish causal chains, provide the evaluative standards against which propositions are evaluated, and chart the options for treatment and action lying ahead [Baden, 2010]. Insofar as the frames are represented by selective links of concepts, those words and concepts are ideological units of life which both reflect and refract particular social relations [Crossley and Roberts, 2004].

Semantic network analysis (SNA) is a form of content analysis which extracts the network of relations between objects as expressed in a text, in order to represent a discursive model as a visible map [Carley and Palmquist, 1992]. Coding texts as maps focuses the user on investigating meaning among texts by finding relationships among words and themes, and by identifying central words in specified relations. In other words, the relative importance of concepts, keywords, can be measured by 'centrality indices'. Moreover, the iterative and statistically significant pattern of referential linkage between keywords can reveal clusters of keywords that represent common themes. The principle of producing the link is based on the measurement of co-occurrences, "defining word-pair link strength as the number of times each word occurs with another, every possible word pair has an occurrence distribution, whose values can range from zero on up" [Danowski, 1993, p. 197]. Word pairs within a window (a word set that becomes an imaginary unit of the document in a word $x$ document matrix) can be given a 'connection weight', either equally regardless of a distance or proportionally to how close the words are [Danowski, 1993]. With these methods, authors studying science communication have identified under-represented metaphors in the debate about artificial sweetners [Hellsten, Dawson and Leydesdorff, 2010], elite media's implicit framing strategies [Kim, 2011] and ordinary people's suppressed desires during South Korean scientist Woo-Suk Hwang's allegation of fraud [Kim, 2013]. 
While the co-occurrence model has become widely used [Jang and Barnett, 1994; Hellsten, Dawson and Leydesdorff, 2010], it is equally important to recognize the sequential relationship between the pair of words that precede or follow each other [Carley and Kaufer, 1993; Kim, 2011]. Conceptual realms are very often hierarchically related, which means that an object $A$ is inferred or thought about within the context of the object $B$, but not vice versa. This psychological assumption implies a potential methodology for classifying keywords [Kronberger and Wagner, 2007, pp. 302-309] with similar patterns of sequence. In automatized analysis with sizable data, this relation can be derived out of the repetitive pattern of syntactic structure in the text ("How many times keyword A precedes B beyond the level of statistical significance?") and presented as a directed edge (arrow).

To do this, a more stable filtering method is required to offer a practical procedure to extract the relevant sequential connections in complex semantic networks, extracting information that would allow a reduced representation, while preserving key features we want to highlight with statistical significance. Mainly applied in statistical physics for extracting complex weighted networks, the 'backbone extraction model' proposed by Serrano, Boguñá and Vespignani Serrano, Boguñá and Vespignani [2009] enables the preservation of statistically significant deviations with respect to a null model that informs us about the random expectation for the distribution of weights associated with the connections of a particular node. ${ }^{3}$ According to the authors [Serrano, Boguña and Vespignani, 2009, pp. 6484-6487], this procedure "determines without arbitrariness how many connections for every node belong to the backbone of connections that carry a statistically disproportionate weight - be they one, zero, or many — providing sparse subnetworks of connected links selected according to the total amount of weight we intend to characterize... An important aspect of this construction is that the ensuing reduction algorithm does not belittle small nodes in terms of strength (frequency) while offering a stable automatic procedure to reduce the number of connections by taking into account all of the scales present in the system. It is possible by applying the disparity filter that exploits local heterogeneity and local correlations among weights to extract the network backbone".

\footnotetext{
${ }^{3}$ According to Serrano, Boguña and Vespignani [2009, p. 6484], the null model that is used to define anomalous fluctuations provides the expectation for the disparity measure of a given node in a pure random case. It is based on the following hypothesis: the normalized weights that correspond to the connections of a certain node of degree $k$ are produced by a random assignment of from a uniform distribution. To visualize this process, $k-1$ points are distributed with uniform probability in the interval $[0,1]$ so that it ends up divided into $k$ subintervals. Their lengths would represent the expected values for the $k$ normalized weights $p_{i j}$ according to the null hypothesis. The probability density function for one of these variables taking a particular value $x$ is:
}

$$
\rho(x) d x=(k-1)(1-x) k-2 d x
$$

The null model allows this discrimination by the calculation for each edge of a given node of the probability $\alpha_{i j}$ that its normalized weight $p_{i j}$ is compatible with the null hypothesis. In statistical inference, this concept is known as the $p$ value, the probability that, if the null hypothesis is true, one obtains a value for the variable under consideration larger than or equal to the observed one. By imposing a significance level $\alpha$, the links that carry weights that can be considered incompatible with a random distribution can be filtered out with an certain statistical significance. All the links with $\alpha_{i j}<\alpha$ reject the null hypothesis and can be considered as significant heterogeneities due to the network-organizing principles. The statistically relevant edges will be those whose weights satisfy the relation

$$
\alpha_{i j}=1-(k-1) \int_{0}^{p_{i j}}(1-x)^{k-2} d x<\alpha
$$


This approach has proved reliable especially for the case of systems with strong disorder, where the weights are heterogeneously distributed (not a normal distribution) just like the semantic network. In our re-analysis of data, a semantic solution ${ }^{4}$ incorporating the key features of the backbone model has been utilized to enable this automatic derivation of core semantic network structure with sequential patterns. The tool also enables the quick search of relevant texts as paragraphes in which derived keywords were frequently used, facilitating the verification of actual meanings the keywords represent.For the analysis, it is important to identify central keywords and their relations with other words to explore the narrative structure and interpret social meanings. Betweenness centrality index [Freeman, 1979] has been frequently used in text analysis [Hellsten, Dawson and Leydesdorff, 2010; Leydesdoff and Schank, 2008] because of its semiotic relevance and statistical robustness. ${ }^{5}$ In communication, interaction between two nonadjacent nodes of concepts is likely to depend on another concept for reference that functions as a "catalysis" to join metalanguages of concepts [Barthes, 1967]. This function is translated into a node with the highest betweenness centrality in the semantic network, when the keyword lies on the paths between the trigger of information and referent, performing a mediating role as a semiological facilitator and a denotative controller of communication [Kim, 2013]. On the other hand, the "flow" or sequence of denotative communication has an ultimate end(s), which becomes a converging point of connotation. This can be represented as an individual keyword or a homogeneous category of word class that has the highest input-closeness centrality [Kim, 2013]. In this study, both keyword and word class with the highest input-closeness centrality are calculated and depicted as 'connotation'. For the thematic categorization of keywords, the Girvan-Newman model [Girvan and Newman, 2002] is utilized after backbone extraction. The Girvan-Newman model clusters nodes according to homogeneous patterns of linkages by iteratively simulating the removal of links from the highest betweenness centrality. This algorithm is relevant for the network structure that is not dependent on the frequency of co-occurrence alone, and much more efficient than hierarchical clustering or other blockmodelling methods [Wasserman and Faust, 1994; de Nooy, Mrvar and Batagelj, 2005; Kim, 2011] in terms of computation. From the perspective of semiotics, a homogeneous linking pattern indicates identical conductivity of discourse, that is, making a similar reference to form an identical theme or a set of synonymous keywords from the discursive context [Jang and Kim, 2013]. Then, the emerging theme can be interpreted both by the author and readers who cross-check the possible common meanings of clustered words. Optimind is an automatic semantic network tool, based on the distance and story line model for coding [Carley, 1993], which extracts and analyzes links among

\footnotetext{
${ }^{4}$ Optimind (version 1.0).

${ }^{5}$ The betweenness centrality of node $v$ in a network is defined as: across all node pairs that have a shortest path containing $v$, the percentage that pass through $v$. The formula is: Let $G=(V, E)$ be the graph representation for the network.

Let $n=|V|$, and fix a node $v V$. For $(u, w) V \times V$,

let this be the number of geodesics in $G$ from $u$ to $w$. If $(u, w) E$, then set $=1$. Define the following: 
words to model the author(s)'s "mental map" as a network of links. By operating the computerized system, the text analysis goes through the following stages:

\section{Preprocessing:}

a. Checking the words and making the list of context-specific thesauri of synonym

b. Automatic lemmatization of variable words (transformation into basic form) based on the English natural language processing (NLP) library and system

c. Automatic deletion of syntactically functional words such as articles and adverbs

2. Processing:

a. Transformation of the remaining text into an adjacency matrix of keywords, with the window size of every paragraph

b. Applying a backbone threshold that extracts core set of nodes (keywords) that fall between 100-200

c. Verifying keywords with high centralities with the original texts in which those keywords were used

3. Visualization

a. Visualization of network by Optimind based on the calculation of centrality indices and grouping algorithm

b. Interpretation of the represented semantic network

To summarize, the latest algorithm of automated semantic network analysis has been utilized in our text analysis. Compared to previous tools and recent noteworthy academic works [e.g. Kwon, Barnett and Chen, 2009; Hellsten, Dawson and Leydesdorff, 2010], it demonstrates a few relative advantages as follows:

- Based on the NLP system of Optimind, automatic lemmatization and grammatical tagging has become possible, which permits more elaborate and reliable coding and processing of textual data

- Novel and reliable representation of sequential relationships in the co-occurrence of keywords has become possible with automatically applied threshold of links by the backbone model

- More intuitive classification of keywords into themes is presented with the Girvan-Newman model and its description that simplifies complex graphes. This enables the direct depiction of the structuralized pattern of relational properties of emerging themes and their consisting keywords besides relying on centrality measures and the 'raw' morphology of the network

In sum, our reanalysis of the data proposes a pathway to interpret and represent different contexts of survey responses from the previously discussed report, as we judge the conventional qualitative analysis tended to be overly selective and could 
not identify salient opinions from an integrative perspective. We claim that this can be done effectively by semantic network analysis. Traditionally, content analysis is a tool for making inferences about the message context. As Krippendorff [2004] argues, a message by itself does not have meaning: it is a set of symbols. The meaning of a message is the connection between these symbols and the things to which they refer. Since each receiver or sender of a message can interpret the message differently, it is important to realize that a message only has a meaning in the "context of its use" [Krippendorff, 2004, p. 33]. As the research question determines which aspects of a message are interesting, it also defines the context in which the message is to be interpreted. The task of content analysis is to "infer" the relevant meaning in that context from the symbols in the message [van Atteveldt, 2008, p. 16].

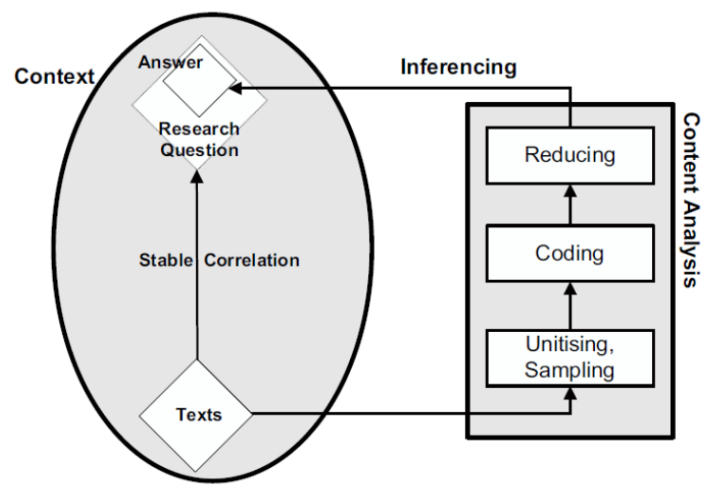

a. Traditional content analysis

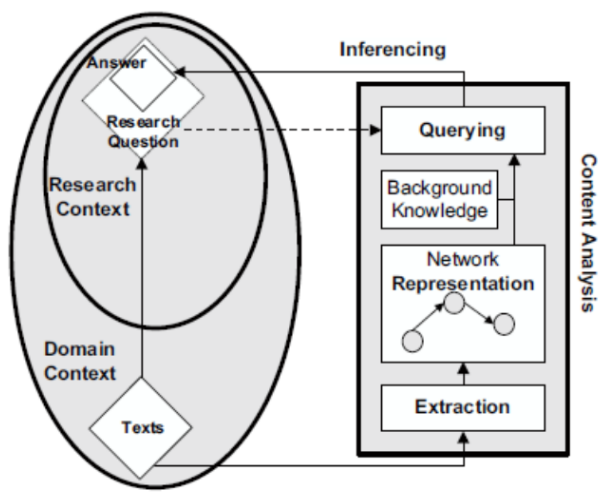

b. Semantic network analysis

Figure 2. The framework of content analysis and semantic network analysis. Source: van Atteveldt [2008, pp. 17, 26]

Figure 2 compares the two approaches. In contrast to the relatively simple procedure of inference derived from the correlation between text and research question in content analysis, SNA goes further, exposing the multilayered contexts of texts and research questions, and proceeds to infer the answer through an active feedback loop between network representation and background knowledge.

Background knowledge is substantiated by an ethnographical review [Tambayong and Carley, 2012] and/or implicitly what sociologist Max Weber refers to as Nach erleben (reliving) through the ideal-typically reconstructed representation.

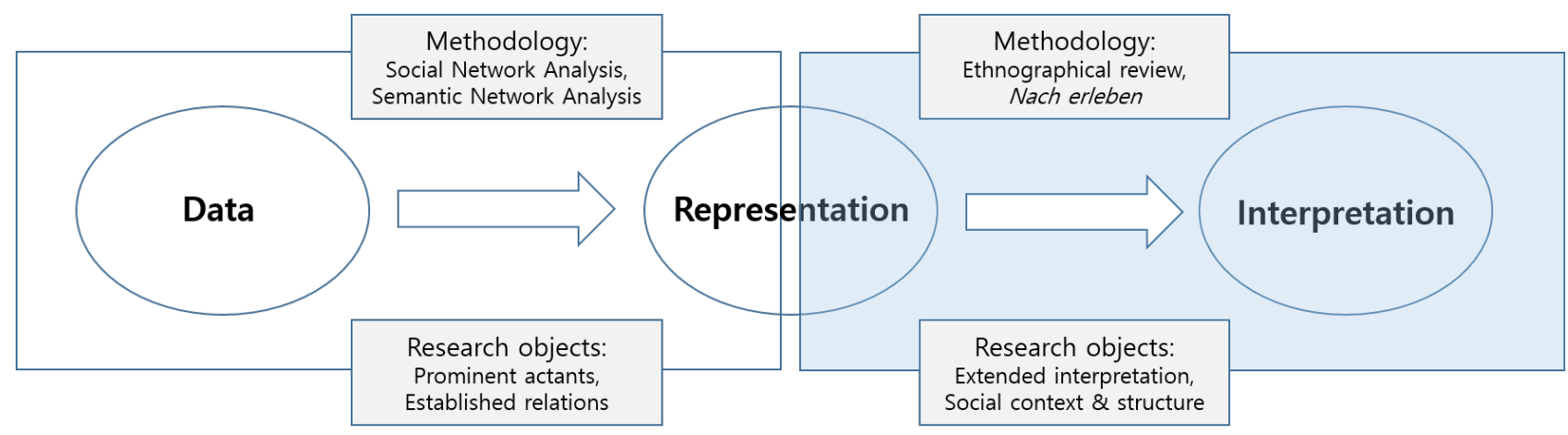

Figure 3. The role of SNA in interpretive sociology. 
As described in Figure 3, the semantic network analysis approach seeks to find prominent actants, which are concepts as central nodes, and their established linkages. The linkages are said to reflect the conductivity of discourse. Although extracting these research objects might be possible without utilizing semantic network, the SNA approaches offer a standardized way to extract core representational characteristics out of large scale unstructured data. Henceforth, the representation undergoes a verification process with collected evidence and counter-evidence: encouraging an ethnographical review of related actors and utterers either confirms or denies the interpretation of social context and structure that are mainly inferred by researcher's experience. Although the answers derived from the review are subjective, the former part of the data processing is an opportunity for the researcher to challenge preexisting notions for interpretation. In this way, we attempt to raise a reasonable doubt against conventional interpretations, not as a form of definitive evidence but as a hypothesis based on the study of relational patterns of semantic network.

Figure 4 is the extracted semantic map ${ }^{6}$ of survey responses that is reorganized by Optimind. Different word classes (themes) by the Girvan-Newman grouping method are presented as different circles, and the directed edges (arrows) and their width respectively represent the sequential flow of statements and the total frequency of linkages between the adjacent word classes. For example, the concept of "research" and related words would precede those of "purpose" and "allow" in Figure 4. The thickness of arrow represents the total frequency of sequential relations, e.g. how many times "research" and containing keywords preceded those of "purpose". Among the words in the same circle, the one with the highest betweenness centrality is placed in the center (for more detail, see Appendix B). In this arrangement, we can detect the core concepts, related words and the sequential flow of identified themes that collectively constuct the patterned frame of respondents' opinion.

Overall, to interprete the diagram, ${ }^{7}$ the core construct of themes and their flow discuss the use of "embryo" for "research", which should be "allow"ed for the "treatment" of "disease" and "agree"ing with the "licensing" "process" in line with the "therapeutic" "purpose".If approval of the research is strongly associated with the therapeutic purpose and licensing regime, the status of embryo induces more complex reflections. The "creation" of embryo and its "regulation" in the case of "human-animal" hybrid and whether to continue the "prohibition" of "cell" "nuclear replacement technique" emerge as focal points of concerns. The underlying rationale in the discussion of the embryo is found in the thematic circle of "human", which incorporates "woman", "body", "egg", "part", "special" and "status" (see Table 1).

By referring to the original text, it turns out that a bioethical perspective is notably manifest in the wordings. For example, Philipa Taylor, the Associate Director of The Centre for Bioethics and Public Policy, in answering Q. 64, claims:

“... The European Parliament (EP) has consequently reminded the European institutions that the human body should not be a source of financial gain and

\footnotetext{
${ }^{6}$ The original backbone network without hierarchical grouping is presented in Appendix A.

${ }^{7}$ The numerical parameters of the depicted diagram are presented in Appendix C.
} 


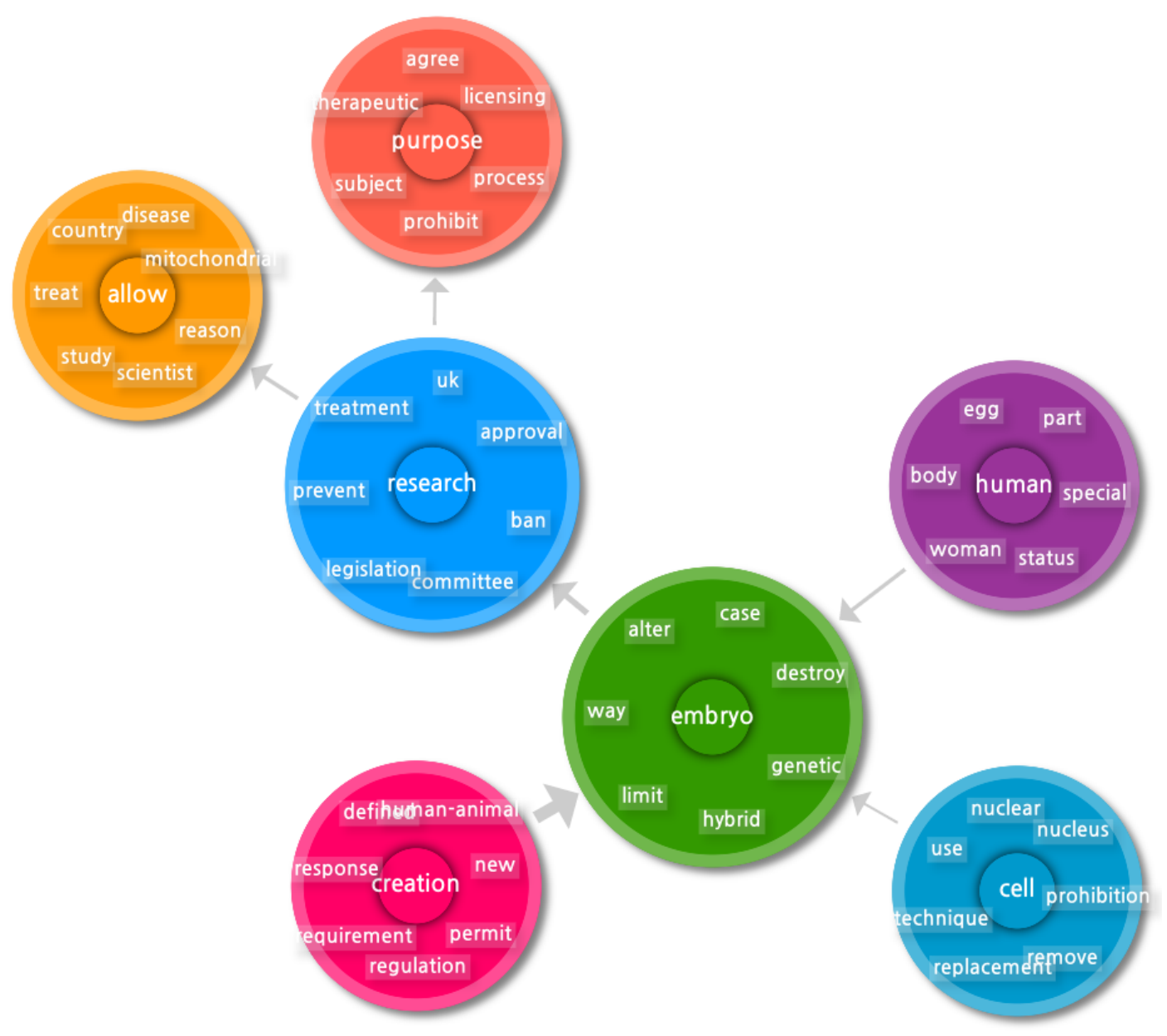

Figure 4. Cognitive map of survey responses.

Table 1. Connected keywords and salient frames.

\begin{tabular}{|c|c|c|c|}
\hline Group & Main word & Related words & Salient frame \\
\hline 1 & Research & $\begin{array}{l}\text { UK, treatment, approval, pre- } \\
\text { vent, ban, legislation, commit- } \\
\text { tee }\end{array}$ & \multirow{3}{*}{$\begin{array}{l}\text { Embryonic stem cell research } \\
\text { can be allowed if it is for } \\
\text { therapeutic purpose such as to } \\
\text { treat mitochondriall disease }\end{array}$} \\
\hline 2 & Allow & $\begin{array}{l}\text { country, mitochondrial, disease, } \\
\text { reason, scientist, study, treat }\end{array}$ & \\
\hline 3 & Purpose & $\begin{array}{l}\text { agree, licensing, process, pro- } \\
\text { hibit, subject, therapeutic }\end{array}$ & \\
\hline 4 & Embryo & $\begin{array}{l}\text { case, destroy, genetic, hybrid, } \\
\text { limit, way, alter }\end{array}$ & \multirow{3}{*}{$\begin{array}{l}\text { Various concerns of destroying } \\
\text { (human) embryo or creating } \\
\text { human-animal embryo }\end{array}$} \\
\hline 5 & Cell & $\begin{array}{l}\text { nuclear, nucleus, prohibition, } \\
\text { remove, replacement, tech- } \\
\text { nique, use }\end{array}$ & \\
\hline 6 & Creation & $\begin{array}{l}\text { human-animal, new, permit, } \\
\text { regulation, requirement, re- } \\
\text { sponse, defined }\end{array}$ & \\
\hline 7 & Human & $\begin{array}{l}\text { part, special, status, woman, } \\
\text { body, egg }\end{array}$ & $\begin{array}{l}\text { Human should be respected, es- } \\
\text { pecially woman's body-egg }\end{array}$ \\
\hline
\end{tabular}


has condemned all trafficking of the human body and its parts: '.. particularly vulnerable individuals at risk of becoming victims of trafficking, particularly women...' The Convention on Human Rights and Biomedicine, not signed of course by the UK, affirms that: 'The human body and its parts shall not, as such, give rise to financial gain or comparable advantage...'. Similarly, the United Nations General Assembly in its Resolution of March 2005 banning human cloning, referred explicitly to the need to prevent the exploitation of women. As stated elsewhere, to determine whether 'good science' is being done, in a way that benefits society, society needs to define exactly what a good end is and what a good means of getting there might be. The 'means' here, egg donation, raises significant medical and ethical issues and cannot be perceived as 'good'".

Josephine Quintavalle, the co-founder of Comment on Reproductive Ethics (CORE), also cautions:

\begin{abstract}
"A proper inquiry into the status quo is required, particularly in relationship to oocyte and embryo 'donation'. Close alliances between fertility centres and research laboratories are undesirable but proliferate, and are a recipe for serious conflicts of interest. It is never in the interests of fertility patients to produce too many embryos, or for a woman to produce excess oocytes. It is, however, of great interest to the research units to obtain as many gametes and embryos as possible".
\end{abstract}

In sum, the derived semantic structure generally reflects the pre-constructed enquiries of the UK government and passive responses to the questionnaires. Under the framework of public consultancy, the current licensing regime of embryo and stem cell research for "therapeutic purpose" has gained the status of an objectified entity, it is a deliberate construct of expert discourse, favoring embryonic stem cell research, in order to fend off public fear of "reproductive (human cloning)" [Jasanoff, 2005; Kim, 2011]. Despite a number of pronounced oppositions to research and any following utilization of the embryo that were mostly based on religious points of view, they are not represented in the core structure of discourses. It is because their wordings stand alone; and did not connect to other common concepts in the semantic network to make a statistically significant mass. The only exception is when they mention the "special status of humans", which comes to be identified with the issue of how "woman's body" will be treated.

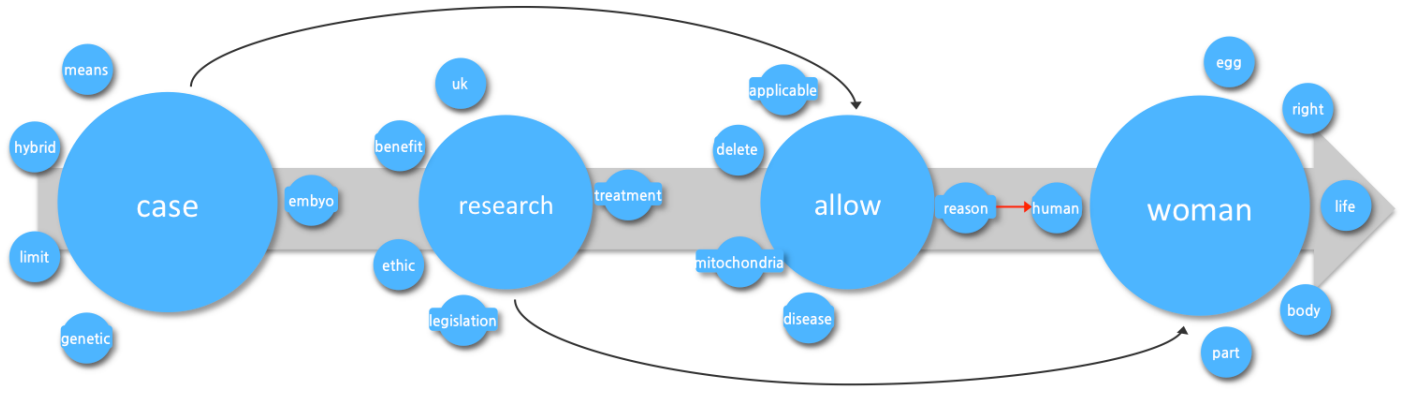

Figure 5. The core story flow of respondents.

This semiotic feature is more clearly represented in the "story flow" representation of Optimind (Figure 5): it applies the threshold of denotation and connotation measures (centralities) and derives hypothetically the most bottom-line discourse 
that can be rearranged in a single linear flow of statements (for mathematical details, see Appendix B). If the denotative theme of [case] becomes the trigger of the statement, the connotative theme of [woman] becomes the converging point of communication. From the perspective of this backbone structure, this algorithm reveals what bottom line story flow, as a hypothetical statement composed of four sub-themes, will remain as the core discourse after removing all the peripheral words and their relations. Reading from left to right, the main argument starts from the denoted [case] of "hybrid" "embryo" and "genetic" manipulation, then proceeding to the "benefit" and "ethic"(al) consideration of [research] in the "UK" and "reason" to treat "disease". Finally, the discussions of "reason" converge on the connotation of [woman] that encompasses the issue of her "body", "egg", and the status of "human" itself. Thus, in a hypothetical statement, "the case of embryo, including the hybrid, [and] its research is discussed in the UK [in regard to] ethical and beneficial angles, including treatment, [and] the matter of allowing the research with derivative aspects such as its usage in mitochondrial disease [eventually converge] to the matter of a human's life and rights, more specifically to women's body parts".

To summarize, with the most stringent application of the threshold for the filtering of information, three characteristics remain as the core frame of responses. Firstly, responses generally follow the constructed pattern of the questionnaires, converging on the discussion of whether to allow controversial research techniques including cell nuclear transfer, genetic transplantation and human-animal hybrid embryos for therapeutic purposes. In this way, the regulating framework of the existing body (HFEA)'s licensing system and the validity of "therapeutic cloning" become the premises of the debate. Secondly, the exceptional dissent that opposes the established structure of embryo research from a religious perspective gains little semiotic status in the systematized analysis. The disappearance of its semantic relevance, in relation to other secular concepts, provides room to reflect upon the diminishing influence of the essentialist debate on human dignity from a religious point of view, when we focus on the general conductivity of debate: how the concepts tend to connect each other. Finally, the abstract value of the "special status of a human" finds both connotative and explicit rationale in the treatment of a woman and her body. In the backbone structure of the discourse pattern, thus, while otherwise docile, the UK public response finds room for subversion, or reclaiming the rights of participation, ultimately in the right of a woman's "egg", or the politics of body.

Conclusion and discussion
Bioethical stances differ from country to country, and there are diverse ways of adopting public views of research regulation. As Sleeboom-Faulkner and Huang note (2012, p. 17), an important question is whether and how discussions are held and shape decision-making, how political mechanisms articulate these as guidelines, and whether or not these guidelines are enforced. In a global atmosphere of increasing standardization and professionalization of bioethics, questions regarding what democratization and public participation mean arise not only in the context of formal processes of participation but also in the context of the mode of semantic representation [Kim, 2012].

From this perspective, there are points of concerns regarding the way the UK government collected and organized the public opinion. It was overly restrictive, 
Table 2. Comparison of extracted opinion, belief and value.

\begin{tabular}{|c|c|c|}
\hline \multicolumn{2}{|c|}{ PSP report } & Iternative interpretation \\
\hline Opinion & $\begin{array}{l}\text { - Emphasis on disagreement } \\
\text { with the use and creation of } \\
\text { embryos for research } \\
\text { - Mixed views regarding CNR } \\
\text { - Juxtaposition of pros and cons } \\
\text { regarding the human-animal } \\
\text { hybrid or chimera embryos } \\
\text { - Little changes for the govern- } \\
\text { ment's list of resesarch pur- } \\
\text { poses needed } \\
\text { - Wide ranging comments on } \\
\text { the desirability of allowing the } \\
\text { creation of embryos for treat- } \\
\text { ment }\end{array}$ & $\begin{array}{l}\text { - Strong central organizing idea } \\
\text { that the embryonic stem cell } \\
\text { research can be allowed if it is } \\
\text { for therapeutic purpose } \\
\text { - Salience of various concerns } \\
\text { of destroying (human) embryo } \\
\text { or creating human-animal em- } \\
\text { bryo } \\
\text { - Semantically important opin- } \\
\text { ion that human should be re- } \\
\text { spected, especially when wo- } \\
\text { man's body part (ova) is util- } \\
\text { ized for the research }\end{array}$ \\
\hline Belief & $\begin{array}{l}\text { - Religious stance against the } \\
\text { possibility of eugenics } \\
\text { - Ethical stance against creating } \\
\text { a child with three genetic par- } \\
\text { ents utilizing CNR }\end{array}$ & $\begin{array}{l}\text { - Semantically weak religious } \\
\text { beliefs that disagree with hu- } \\
\text { man embryonic stem cell re- } \\
\text { search } \\
\text { - Sentiment agaisnt the hybrid } \\
\text { or chimera should be respec- } \\
\text { ted }\end{array}$ \\
\hline Value & $\begin{array}{l}\text { - Precautionary principle for } \\
\text { safety } \\
\text { - Cure for patients } \\
\text { - Scientific enhancement }\end{array}$ & $\begin{array}{l}\text { - Denotative value: research for } \\
\text { therapeutic purpose } \\
\text { - Connotative value: human } \\
\text { right realized through the re- } \\
\text { spect to woman's body }\end{array}$ \\
\hline
\end{tabular}

and inevitably made the discrete opinions selectively representable. The alternative interpretation presented in Table 2 does not replace the valuable insights derived in the PSP report, as our method delimited outselves to focus on the salient form of discourses from the semantic network perpective. They must be mutually conplementary. However, the identified gaps also call for more comprehensive surveying and a novel form of analysis in order to map the opinion, belief and value of the "representative sample", and then engage in a deeper ethnographical reflection in the future.

So far, the UK government has shown a variety of practices committed to include the lay public in the highly complex scientific decision-making process mainly to cope with the "crisis of confidence" after the GM food and BSE crises [POST, 2001]. Recent desk research commissioned by BBSRC and MRC [OPM, 2007] identifies five major public engagement initiatives (The Stem Cell Dream, North Cumbria Community Genetics Project, public debate on hybrid embryos and public perception of stem cell research), five main public consultations (including the one 
described here), and a few other surveys and opinion polls with respect to stem cell research that are conducted either by the government or public organizations.

As highlighted in this research, however, "the 'problem of legitimacy' (of experts) replaced by the 'problem of extension' of (public participants)" [Collins and Evans, 2002 , p. 1] may not lead to simply extending the formal boundary of participants in scientific decision-making. It can raise more profound question about:

\footnotetext{
"how public issues are framed and thus given meaning, unveiling the neglected questions about how proper knowledge for relatively new domains should be negotiated as matters of "civic epistemology", and how we have by default allowed previously institutionalized epistemic commitments to be extended to such domains with inadequate collective reflection and debate, shedding new light on its hidden context, public meanings and representations" [Wynne, 2002, p. 402-405].
}

In this regard, the UK governance process reveals how opposition to embryo research, and hybrid or chimera embryos in particular, has eventually been overrun by the decision-making Parliament and scientific experts [Kim, 2012]. And providing therapeutic solutions for the sake of the "common good" has become the dominant discourse. From our analytical perspective, the weakenss of the lay public's discourse in the UK, could be observed in the lack of articulation of "secular" causes and their strategic linkages to other social issues. When mainly viewed through the semiotic arrangement of data, the unique issue of a woman's body, and the politicization of ova, seems to represent a socially effective argument. This resonates with Giddens [1991]' classical project of "emancipatory life politics", by means of politicizing the personal body in Western society. In this manner, existing social arguments revisit the place of life sciences.

As mentioned before, the limitation of our research is that the represented network characteristics do not lead to a confirmatory conclusion. Rather, as implicated in Table 2. [value] row, the result recasts the question how to position the denotative value of therapeutic stem cell research within the deliberation of connotative value, that is, human rights concretely realized through the governing of body parts.

Although this does not raise any novel question in its own right, the result reaffirms the basis of scientific legitimacy at least represented by the Western (British) public, whereas utilizing unlicensed ova did not raise any serious concern among the public on the other part of globe such as South Korea [Kim, 2009; Kim, 2008]. When considering the practical pathway of ethical supervision and democratic participation in life science, to paraphrase Sleeboom-Faulkner et al. [Sleeboom-Faulkner and Huang, 2012, p. 22]'s comment, the mode of democratic participation including public consultation "may actually be more effective when those engaged with the material and political aspects of human embryonic stem cell research are practically encouraged to develop their views and are given serious consideration, rather than by creating a "democratic" system to poll all representative views" (italic inserted by authors). Thus, the professionalization of bioethics and expert-dominant culture witnessed in developed countries evokes the question: "Are those who speak really able to legitimately say what they mean to deliver?" The methodological efforts to uncover different aspects of social characteristics, we believe, should be able to respond to the question. 
Acknowledgments The authors are grateful to Dr. Emma Weitkamp and the anonymous referees who offered valuable advice to improve our work. We also thank the computer scientist Dr. Haewoon Kwak who initially introduced the method of backbone extraction model for reliable data filtering and advanced network analysis.

Appendix A. The same color of nodes represents an identical Girvan-Newman group.

The original

backbone

network

(of Figure 4)

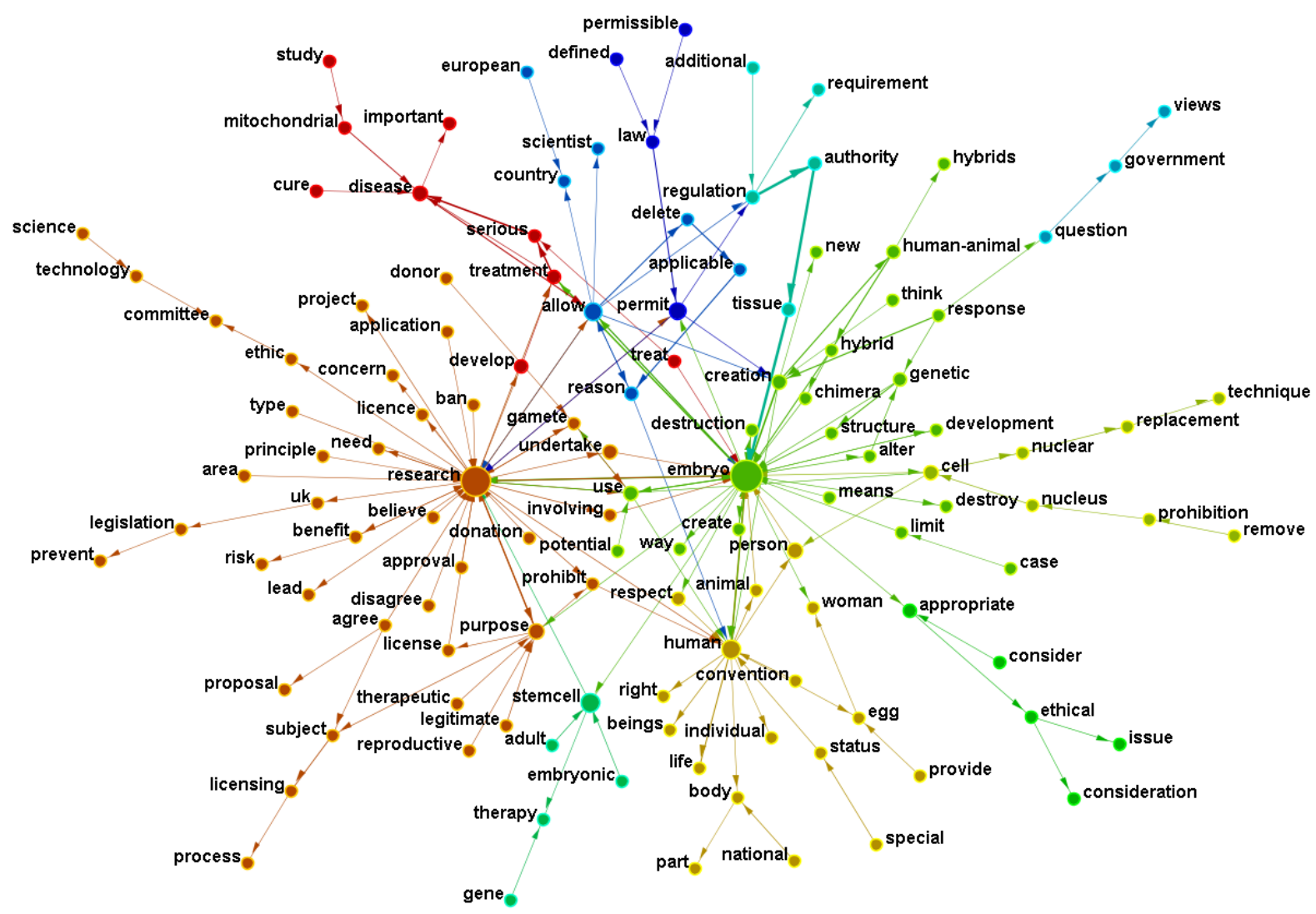

*Graphic produced by ORA 
Appendix B.

The mathematical

process of

"story flow"

The mathematical logic of "story flow" model (represented in Figure 5).

1. Let $B=\left(V_{B}, E_{B}\right)$ denote backbone network where $V_{B}$ is a set of vertices in $B$ and $E_{B}$ is a set of edges in $B$.

2. By Newman-Girvan method, each vertex in $V_{B}$ is assigned on $i$ th group, where $i=1,2, \ldots, n$. $n$ is the total number of groups. Then define a set of nodes $S_{i}$ as $S_{i}=\left\{v \in V_{B} \mid v\right.$ has group number $\left.i\right\}$. Also, we can define weighted edge between $S_{i}$ s. Let $E_{S}$ be a set of edges $e_{i, j}$ between two groups of nodes $S_{i}$ and $S_{j}$, such that

$$
e_{i, j}=\sum_{x \in S_{i}, y \in S_{j}} \begin{cases}e_{B}(x, y) & \text { where } e_{B}(x, y) \in E_{B} \\ 0 & \text { otherwise }\end{cases}
$$

Surely, $E_{S}$ is not symmetric.

3. Let flow denote $F$ as;

(a) $F=\left(V_{F}, E_{F}\right)$ where $V_{F}=\left\{S_{i_{1}}, S_{i_{2}}, S_{i_{3}}, S_{i_{4}}\right\}$ and $i_{1} \ldots i_{4}$ is in $\{1,2, \ldots, n\}$

(b) $S_{i_{4}}=\max _{k=1, \ldots, n} \operatorname{Input} \operatorname{Closeness}\left(S_{k}\right)$. If $\max _{k=1, \ldots, n}$ Output Closeness $\left(S_{k}\right)$ is connected with $S_{i_{4}}$, then $S_{i_{1}}=\max _{k=1, \ldots, n}$ Output $\operatorname{Closeness}\left(S_{k}\right)$. Otherwise $S_{i_{1}}$ is chosen by next maximization step.

(c) With fixed $i_{4},\|F\| \geq\left\|\left(V_{i, j, k, i_{4}}=\left\{S_{i}, S_{j}, S_{k}, S_{i_{4}}\right\}, E_{i, j, k, i_{4}}\right)\right\|$, where $i \neq j \neq k \neq i_{4}$ and $\forall i, \forall j, \forall k \in$ $\{1,2, \ldots, n\}$

$\|F\|$ is 1-dimensional norm, defined as $\|F\|=\left\|S_{i_{1}}, \ldots, S_{i_{j}}\right\|=\sum_{k=1}^{j-1}\left(e_{i_{k}, i_{k+1}}-e_{i_{k+1}, i_{k}}\right)$

4. Define $O C(x)$ and $B C(x)$ as;

(a) $O C(x): S \rightarrow R^{+}$where $S$ is a set of sets which contains vertices in Network, and $R^{+}$is a set of positive real number. A range of $O C(x)$ is a set with one element, which is Output Closeness of $x$.

(b) $I C(x): S \rightarrow R^{+}$where $S$ is a set of sets which contains vertices in Network, and $R^{+}$is a set of positive real number. A range of $I C(x)$ is a set with one element, which is Input Closeness of $x$.

(c) $B C(x): S \rightarrow R^{+}$where $S$ is a set of sets which contains vertices in Network, and $R^{+}$is a set of positive real number. A range of $B C(x)$ is a set with one element, which is Betweenness Cenrality of $x$.

5. In each $S_{i}$ in flow, choose its representative vertex such as

$\begin{array}{cc}\text { Case of } S_{i} & \text { Representative vertex } \\ S_{i_{1}} & \max _{x \in S_{i_{1}}} O C(x) \\ S_{i_{2}} & \max _{x \in S_{i_{2}}} B C(x) \\ S_{i_{3}} & \max _{x \in S_{i_{3}}} B C(x) \\ S_{i_{4}} & \max _{x \in S_{i_{4}}} I C(x)\end{array}$

6. Also, choose 10 vertices(words) in each $S_{i}$ of flow such as;

Case of $S_{i} 10$ Vertices

$S_{i_{1}} \quad\left\{x_{j_{1}}, \ldots, x_{j_{10}} \mid j_{k}\right.$ is descending order of $\left.O C(x)\right\}$

$S_{i_{2}} \quad\left\{x_{j_{1}}, \ldots, x_{j_{5}} \mid j_{k}\right.$ is descending order of $\left.O C(x)\right\} \cup\left\{x_{j_{1}}, \ldots, x_{j_{5}} \mid j_{k}\right.$ is descending order of $\left.I C(x)\right\}$

$S_{i_{3}} \quad\left\{x_{j_{1}}, \ldots, x_{j_{5}} \mid j_{k}\right.$ is descending order of $\left.O C(x)\right\} \cup\left\{x_{j_{1}}, \ldots, x_{j_{5}} \mid j_{k}\right.$ is descending order of $\left.I C(x)\right\}$

$S_{i_{4}} \quad\left\{x_{j_{1}}, \ldots, x_{j_{10}} \mid j_{k}\right.$ is descending order of $\left.I C(x)\right\}$

Each 5 vertices appear in both side of a vertex in flow and represent their edge if they exist. 
Appendix C. Numerical properties of Table 1

The list of betweenness centrality measures of each keyword in Table 1.

\begin{tabular}{|l|l|l|l|l|l|}
\hline \multicolumn{2}{|c|}{ Group 1 } & \multicolumn{2}{c|}{ Group 2 } & \multicolumn{2}{c|}{ Group 3 } \\
\hline Keyword & $\begin{array}{l}\text { Centrality. } \\
\text { Between- } \\
\text { ness }\end{array}$ & Keyword & $\begin{array}{l}\text { Centrality. } \\
\text { Between- } \\
\text { ness }\end{array}$ & $\begin{array}{l}\text { Keyword } \\
\text { Between- } \\
\text { ness }\end{array}$ \\
\hline research & 0.179018 & allow & 0.085016 & purpose & 0.035361 \\
\hline treatment & 0.0189 & disease & 0.034684 & subject & 0.010161 \\
\hline uK & 0.010161 & reason & 0.011313 & licensing & 0.005148 \\
\hline legislation & 0.005148 & mitochondrial & 0.005148 & prohibit & 0.001355 \\
\hline approval & - & country & - & agree & - \\
\hline prevent & - & scientist & - & process & - \\
\hline ban & - & study & - & therapeutic & - \\
\hline committee & - & treat & - & & \\
\hline
\end{tabular}

\begin{tabular}{|l|l|l|l|l|l|l|l|}
\hline \multicolumn{2}{|c|}{ Group 4 } & \multicolumn{2}{c|}{ Group 5 } & \multicolumn{2}{c|}{ Group 6 } & \multicolumn{2}{c|}{ Group 7 } \\
\hline Keyword & $\begin{array}{l}\text { Centrality. } \\
\text { Between- } \\
\text { ness }\end{array}$ & Keyword & $\begin{array}{l}\text { Centrality. } \\
\text { Between- } \\
\text { ness }\end{array}$ & Keyword & $\begin{array}{l}\text { Centrality. } \\
\text { Between- } \\
\text { ness }\end{array}$ & $\begin{array}{l}\text { Keyword } \\
\text { Between- } \\
\text { ness }\end{array}$ \\
\hline embryo & 0.212742 & cell & 0.029784 & creation & 0.036987 & human & 0.069593 \\
\hline genetic & 0.011855 & use & 0.026814 & permit & 0.034345 & status & 0.005148 \\
\hline hybrid & 0.009823 & nucleus & 0.010297 & regulation & 0.019713 & nody & 0.005148 \\
\hline alter & 0.009687 & nuclear & 0.010161 & human-animal & 0.014835 & egg & 0.000339 \\
\hline limit & 0.005148 & prohibition & 0.005216 & response & - & part & - \\
\hline case & - & replacement & 0.005148 & new & - & special & - \\
\hline destroy & - & remove & - & requirement & - & woman & - \\
\hline way & - & technique & - & defined & - & & \\
\hline
\end{tabular}

References

Baden, C. (2010). 'Communication, Contextualization and Cognition: Patterns and Processes of Frames' Influence on People's Interpretations of the EU Constitution'. Ph.D. Thesis. University of Amsterdam, The Netherlands.

Barthes, R. (1967). Elements of Semiology. trans. A. Lavers and C. Smith. New York, U.S.A.: Jonathan Cape Ltd.

Bourdieu, P. (1991). Language and Symbolic Power. Cambridge, U.K.: Polity Press. Carley, K. (1993). 'Coding choices for textual analysis: A comparison of content analysis and map analysis'. Sociological Methodology 23, pp. 75-126.

Carley, K. and Kaufer, D. (1993). 'Semantic connectivity: An approach for analyzing symbols in semantic networks'. Communication Theory 3 (3), pp. 183-213.

Carley, K. and Palmquist, M. (1992). 'Extracting, representing, and analyzing mental models'. Social Forces 70 (3), pp. 601-636.

Collins, H.M. and Evans, R. (2002). 'The Third Wave of Science Studies: Studies of Expertise and Experience'. Soc. Stud. Sci. 32, p. 235.

Crossley, N. and Roberts, J.M., eds. (2004). After Habermas: New Perspectives on the Public Sphere. Oxford, U.K.: Blackwell.

Danowski, J.A. (1993). 'Network Analysis of Message Content'. In: Progress in Communication Sciences 12. Ed. by W.D. Richards and G.A. Barnett. Norwood, NJ, U.S.A.: Albex, pp. 197-220.

de Nooy, W., Mrvar, A. and Batagelj, V. (2005). Exploratory Social Network Analysis with Pajek. Cambridge, U.K.: Cambridge University Press. 
Durant, J., Bauer, M. and Gaskell, G., eds. (1998). Biotechnology in the Public Sphere: A European Sourcebook. London, U.K.: Science Museum.

Foucault, M. (2002). The Order of Things. New York, U.S.A.: Routledge.

Freeman, C. (1979). 'Centrality in networks: Conceptual clarification'. Social Networks 1, pp. 215-239.

Giddens, A. (1991). Modernity and Self-Identity: Self and Society in the Late Modern Age. Stanford, U.S.A.: Stanford University Press.

Girvan, M. and Newman, M. (2002). 'Community structure in social and biological networks'. In: National Academy of Sciences of the U.S.A. DOI: 10.1073/pnas. 122653799.

Hellsten, I., Dawson, J. and Leydesdorff, L. (2010). 'Implicit media frames: Automated analysis of public debate on artificial sweeteners'. Pub. Underst. Sci. 19 (5), pp. 590-608.

House of Commons (2002). Developments in Human Genetics and Embryology.

HC 791. URL: http://www . publications . parliament.uk/pa/cm200102/ cmselect/cmsctech/791/791.pdf.

Human Genetics Advisory Commission (1998). Cloning Issues in Reproduction, Science and Medicine. URL:

http://www.advisorybodies.doh.gov.uk/hgac/papers/papers_c.htm (visited on 4th September 2012).

Jang, D. and Kim, L. (2013). 'Framing 'world class' differently: international and Korean participants' perceptions of the world class university project'. Higher Education 65 (6), pp. 725-744.

Jang, H. and Barnett, G. (1994). 'Cultural Differences in Organizational Communication: A Semantic Network Analysis'. Bulletin de Methodologie Sociologique 44, pp. 31-59.

Jasanoff, S. (2005). Designs on Nature. Princeton, U.S.A.: Princeton University Press. Kim, J. (2009). 'Public feeling for science: The Hwang affair and Hwang supporters'. Pub. Underst. Sci. 18 (6), pp. 670-686.

Kim, L. (2008). 'Explaining the Hwang scandal: National scientific culture and its global relevance'. Science as Culture 17 (4), pp. 397-415.

- (2011). 'Media framing of stem cell research: a cross-national analysis of political representation of science between the UK and South Korea'. JCOM 10 (3), A02. URL: http://jcom. sissa.it/archive/10/03/Jcom1003(2011)A02.

- (2012). 'Governing discourses of stem cell research: Actors, strategies and narratives in the UK and South Korea'. East Asian Science, Technology and Society: an International Journal 6 (4), pp. 497-518. DOI: 10.1215/18752160-1730771.

- (2013). 'Denotation and connotation in public representation: semantic network analysis of Hwang supporters' internet dialogues'. Pub. Underst. Sci. 22 (3), pp. 335-350.

Krippendorff, K. (2004). Content Analysis: An Introduction to its Methodology. Thousand Oaks, CA, U.S.A.: Sage.

Kronberger, N. and Wagner, W. (2007). Keywords in context: Statistical analysis of text features. in M. Bauer and G. Gaskell eds., Qualitative Researching with Text, Image and Sound. London, U.K.: SAGE.

Kwon, K., Barnett, G.A. and Chen, H. (2009). 'Assessing cultural differences in translation-based communication: Semantic network analysis of multilingual translations of the Universal Declarations of Human Rights'. Journal of Intercultural and International Communication 2(2), pp. 107-138. 
Leydesdoff, L. and Schank, T. (2008). 'Dynamic Animations of Journal Maps: Indicators of Structural Changes and Interdisciplinary Developments'. Journal of the American Society for Informaiton Science and Technology 59 (1), pp. 1810-1818. arXiv: 0911.1437.

OPM (2007). Stem Cell Public Dialogue: Final Report for BBSRC and MRC. POST (2001). Open Channels: Public Dialogue in Science and Technology.

PSP (March 2006). Report on the Consultation on the Review of the Human Fertilisation \& Embryology Act 1990.

Serrano, K.A., Boguñá, M. and Vespignani, A. (2009). 'Extracting the Multiscale Backbone of Complex Weighted Networks'. Proceedings of the National Academy of Sciences of the U.S.A. 106 (16), pp. 6483-6488.

Sleeboom-Faulkner, M. and Huang, S. (2012). 'Governance of Stem Cell Research: Public Participation and Decision-Making in China, Japan, South Korea and Taiwan'. Soc. Stud. Sci. 42 (5), pp. 684-708. DOI: 10 .1177/0306312712450939.

Strauss, A. and Corbin, J.M. (1990). Basics of qualitative research: Grounded theory procedures and techniques. Thousand Oaks, CA, U.S.A.: Sage.

Tambayong, L. and Carley, K. (2012). 'Network Text Analysis in Computer-Intensive Rapid Ethnography Retrieval: An Example from Political Networks of Sudan'. Journal of Social Structure 13, p. 1.

Tewksbury, D. and Scheufele, D.A. (2009). News framing theory and research. in J. Bryant and M.B. Oliver eds., Media effects: Advances in theory and research. New York, U.S.A.: Routledge.

UK Department of Health (2005). Human Reproductive Technologies and the Law: Government Responses to the Report from the House of Commons Science and Technology Committee. URL: http://www.dh.gov.uk/en/Publicationsandstatistics/Publications/ PublicationsPolicyAndGuidance/DH_4117875 (visited on 1st February 2012).

UK Department of Health and Social Security (1984). Report of the Committee of Inquiry into Human Fertilisation and Embryology. London, U.K.: Her Majesty's Stationery Office. URL: http://www.hfea.gov.uk/docs/Warnock_Report_of_the_Committee_of_ Inquiry_into_Human_Fertilisation_and_Embryology_1984.pdf.

van Atteveldt, W. (2008). Semantic Network Analysis: Techniques for Extracting, Representing, and Querying Media Content. Amsterdam, The Netherlands: Vrije Universiteit Amsterdam.

Wasserman, S. and Faust, K. (1994). Social Network Analysis: Methods and Applications. New York, U.S.A.: Cambridge University Press.

Wynne, B. (2002). 'Seasick on the Third Wave? Subverting the Hegemony of Propositionalism: Response to Collins \& Evans'. Soc. Stud. Sci. 33, p. 401. 
Leo Kim is the president of data analysis and consulting firm Ars Praxia. He studies science and political communication from the perspective of data analysis with the methodological approach of semantic network analysis. He graduated University of Sussex for his PhD. E-mail: leo_kim@arspraxia.com

Namhyeok Kim is the CTO of Ars Praxia. He studied computer science and is currently developing automatized text-mining and semantic network analysis system. E-mail: Namhyeok_kim@arspraxia.com

Kim, L. and Kim, N. (2015). 'Connecting opinion, belief and value: semantic network analysis of a UK public survey on embryonic stem cell research'. JCOM 14 (01), A01. 